De-colonizing Listening: Toward an Equitable Approach to Speech Training for the Actor

Daron Oram

Royal Central School of Speech and Drama, London, UK

daron.oram@cssd.ac.uk

Daron Oram is a Senior Lecturer in Voice, working with students on both the BA acting: collaborative and devised theatre and the MA/MFA in voice studies: teaching and coaching programs at the Royal Central School of Speech and Drama. Daron's practice-based research focuses on equitable training practices as well as the intersection of psychophysical approaches to acting and voice. Daron is an alumnus of the Central voice course, a Designated Linklater Teacher, and a Senior Fellow of the Higher Education Academy. 


\title{
De-colonizing Listening: Toward an Equitable Approach to Speech Training for the Actor
}

\begin{abstract}
This article confirms and deepens an understanding of the negative impact of teaching culturally embedded speech standards to actors who are "othered" by a dominant "somatic norm" within the performing arts. The author analyzes evidence from a three-year longitudinal study of actors within a UK conservatory in relation to the critical frame of the somatic norm and colonized listening practices in the performing arts. The author identifies conscious and unconscious bias within traditional training methods and proposes a decolonizing approach to listening within foundational speech training. The ideological shift outlined follows the "affective turn" in the humanities and social sciences and moves away from the culturally embedded listening at the core of "effective" speech methods, which focus solely on clarity and intelligibility. The outcome of this research is a radical performance pedagogy, which values the intersectional identities and linguistic capital of students from pluralistic backgrounds. The revised curriculum offers an approach to affective speaking and listening that assumes an equality of understanding from the outset, and requires actors, actor trainers, and, ultimately, audiences to de-colonize their listening ears.
\end{abstract}

\section{Key words}

speech training, received pronunciation, decolonizing, acting, diversity, equity, affect

\section{Introduction}

In 2017 the UK Labour party produced a report into access and diversity in the performing arts. In this report, actress, Cush Jumbo, describes how her training impacted on her sense of class and ethnicity:

It wasn't until I went to Central drama school that I actually looked in the mirror and realized I was of color. I nearly left at the end of my first year because I felt so uncomfortable, so working class. I remember being told by the teacher who I was studying received pronunciation with that my accent was lazy, that South Londoners had lazy mouths and lazy accents. (Brabin, De Piero, and Coombes 2017, 12)

In 2012, Catherine McNamara and Nicholas Coomber published their research findings, BME Student Experiences at Central School of Speech and Drama: ${ }^{1}$

One of the most notable themes to emerge was a feeling of isolation or alienation amongst their peers $[\ldots]$ Others $[\ldots]$ felt that social class had an equal if not more significant effect [...] "If you come from a certain kind of background and certain conventions are familiar to you, then you can walk through Central with more ease." McNamara and Coomber 2012, 19-20)

The issues of race and class highlighted here are not limited to Central School. In her 2015 article, Amy Ginther identifies structures of dysconscious racism across British actor training (Ginther 2015). Ginther draws on a 2009 Conference of Drama Schools survey looking at 
BME Student experiences across a range of UK Conservatories, which revealed a "widespread problem" (Ginther 2015). Ginther's own research includes a broad survey of mainstream British voice pedagogy and examines the liberal humanist tradition of voice training, along with approaches to text work, racism, and critical pedagogy and a brief discussion of Received Pronunciation (RP) as a speech standard. Ginther conducted five structured interviews with students and recent graduates from pluralistic backgrounds who were taught on a range of UK conservatory courses and her findings "illuminate a need for a more engaged and critical consciousness surrounding mainstream British voice pedagogy and its assumptions, given the increasingly diverse populations within conservatory classrooms" (Ginther 2015, 55). In this article, I respond to the recurrent evidence of racial and class discrimination across the various UK research projects cited above and share innovative practice that aims to answer Ginther's call for change.

As well as expanding the UK perspective, this research responds to and extends the US debate around the teaching of accent standards. The American speech debate emerged in the first edition of the Voice and Speech Trainers Association (VASTA) journal, the Voice and Speech Review (VSR) (Dal Vera 2000). That edition of the VSR discussed "Standard American Stage" speech ${ }^{2}$ and focused significantly on race and ethnicity, a discussion that has been revisited on several occasions (McGee 2005; Espinosa and Ocampo-Guzman 2010; Espinosa 2011; Tonning-Kollwitz and Hetterly 2018). This article expands the US discussion beyond race and ethnicity to recognize the impact of standard speech systems on other intersectional identities, including, but not limited to, class and regionality.

The full research project encompasses two strands. The first investigates foundational speech and articulation training for actors, and the second explores approaches to the more transformative work of accent and dialect training. This article focusses on the first of these two strands, looking at foundational speech training that generally occurs in the first year of three-year conservatory actor training programs, before the more transformational work of accents and dialects in year two.

\section{Methodology}

This research project employs a heuristic case study methodology. The research employed focus groups to understand student experiences along with a reflective practice approach to develop a new curriculum for speech training on the BA Acting Collaborative and Devised Theatre program (BA Acting-CDT) at the Royal Central School of Speech and Drama (Central). This core case study is enhanced by a wider investigation of UK actor experiences and industry perspectives and engages in dialogue with the existing research outlined above.

Voice and speech trainer, Dudley Knight, states:

If we fail to re-examine periodically, and with rigor, the basic assumptions on which our teaching is founded (not just the practical details and techniques) we may [...] be promoting unconsciously practices that run directly counter to our own best intentions. $(2000,64)$

The research outlined here responds to Knight and Ginther's call for a critical engagement with assumptions and unconscious or dysconscious practices. By using a heuristic methodology, I have been able to investigate and challenge my own values and belief systems within a rigorous research framework. Clark Moustakas's heuristic methodology comprises of six stages: "initial engagement," "immersion," "incubation," "illumination," "explication," and "creative synthesis" (Moustakas 1990) and "can be characterized by a willingness to surrender to the research question, to a sufficient extent that a personal 
transformation can take place." "The ultimate product [...] is a story of personal transformation that has the potential to transform others" (McLeod 2011, 207). It is my hope that by sharing my story I can inspire and engage others' practices.

Shauneen Pete, a Cree/Salteaux/Dakota scholar, describes the practice of storytelling as "a decolonizing strategy" and notes that the "choice to decolonize knowledge transmission troubles dominant ideas about what scholarship should look like, especially as articulated in the discourse norms of higher education" (Pete 2018, 173-4). The research outlined in this article takes a decolonizing turn, and sharing the affect (sic) of this process, rather than letting it be subsumed into pure academic discourse, maintains the political drive at the heart of this work.

The research centers around a three-year longitudinal study of the experiences of three full cohorts of students on the BA Acting-CDT program. To help students share their experiences more openly an external facilitator was employed to run a series of focus groups. These focus group recordings became critical in the heuristic research process. Moustakas's methodology requires the researcher to engage in a deeper understanding using processes of: "identifying with the focus of enquiry," "tacit knowing," "focusing," "indwelling," "intuition," "self-dialogue," and "internal frame of reference" (Moustakas 1990). By sitting with the focus group recordings and listening deeply, I was able to identify with the enquiry and, through a process of indwelling, engaged with intuition and self-dialogue that had the power to disrupt my unconscious beliefs and practice.

Dudley Knight highlights that when evaluating the values of and approaches to actor training, there is additional rigor and value to be found in "interdisciplinary links" (Knight 2000, 64). My research has accordingly been subject to analysis through the interdisciplinary critical lenses of applied theatre, critical pedagogy, sociology, sound studies, and sociolinguistics.

Whilst heuristic research does have six clear stages, the experience of living through the process is much more organic and some of the stages can blur into one another or be revisited a number of times. In an attempt to orient the reader with the research, I offer the following timeline of events. An initial focus group was held with graduating students to discuss their experiences, after which, I developed an outline for a new curriculum and facilitated discussions and revisions with my teaching colleagues, Deborah Garvey and Louise Jones ${ }^{3}$. The revised curriculum was delivered to incoming first-year students and some minor revisions were made to the ongoing second-year curriculum. Two further focus groups were held, one with the cohort who had experienced the minor changes, the other with the cohort who experienced the fully revised curriculum. The curriculum was further revised for the next cohort of students and their responses to the first year of work were collected through in class discussions, peer observation, reflective teaching practice involving close journaling.

The primary findings of the case study are limited to the Acting-CDT program. To broaden the validity and relevance of this project another layer of research ran concurrently with the practiced-based research. This involved the examination of existing research in this area along with the development of the interdisciplinary critical framework. Additionally, qualitative and quantitative data was gathered from across the UK conservatory and performing arts sector. This wider research aimed to test the validity of the primary findings beyond the immediate practice-based case study and helped to avoid any seeming collapse of academic rigor toward the personal subjectivities of heuristic research. Alongside the development of the revised curriculum I held structured interviews with three directors, three casting directors, three agents, and four voice coaches. Across each of these disciplines, participants were chosen who represented small scale contemporary theatre, commercial theatre television and film, and subsidized national theatre companies - their responses have 
been anonymized. During the final year of the practice-based research, I carried out a survey of 58 actors who had been trained across a range of UK institutions The survey participants self-selected via social media requests. Finally, the emergent practices from the research were discussed and debated with 50 practitioners, representing a large percentage of UK training institutions, at an Inclusive Practice Forum for voice teachers held at Central in April 2018. Analysis of the data from this wider research beyond the Acting-CDT case study indicates that the practice-based findings are applicable across UK training and beyond.

\section{Industry Demands, Student Experience, and the "Somatic Norm"}

The BA Acting-CDT course is "an innovative and rigorous actor training, emphasizing the creation of new theatre" and "embraces a multicultural and multidisciplinary methodology" (RCSSD 2018). Whilst the course does engage with practice and approaches to theatre making beyond psychological realism, at the heart of its acting pedagogy is a clear thread of naturalism. ${ }^{4}$ Accordingly, this research situates itself within the dominant mode of psychological realism common to most UK conservatory training ${ }^{5}$ and engages with the interface between the experiences of students during training, their career aspirations, and the needs and perceptions of the industry.

In their article on typecasting in British acting, Sam Friedman and Dave O'Brien (2017) describe how the "skew in the supply of 'types' in British acting is formational [...] in establishing and designating the white, male, middle-class body as the industry's somatic norm" $(2017,8)$. They draw the concept of the somatic norm from Nirmal Puwar's (2004) publication, Space Invaders: Race, Gender and Bodies out of Place and use it to describe the "white, male, upper/middle class body" that is "so naturalized [...] that it acts to deny any conception of this subject as classed, gendered and-particularly-raced" (5-6). In this article, I use the term "somatically othered" to describe actors and students who are othered because their intersectional identity does not conform to the white, male, middle to upper class somatic norm of the performing arts industry.

The increasingly embedded nature of actor training within UK Higher Education further impacts the experiences of somatically othered students. Sociologist, Kalwant Bhopal, describes Higher Education institutions as "spaces of white privilege which fail to cater for the experiences of BME groups. They employ a rhetoric of inclusion, but one that is rarely evident in practice or outcomes" (Bhopal 2018). The opening quotes above evidence how the white privilege of higher education intersects with the somatic norm of the performing arts to reinforce the negative experiences of somatically othered students.

This article focusses on the first strand of my research: first-year foundational speech training. The quote below comes from the first focus group with students who had been trained in speech using traditional methods combining RP, articulation and the International Phonetic Alphabet (IPA). This comment, from a graduating student who identifies as black and working-class, captures some of the key points raised so far:

I feel since coming here my native accent is not good enough. This line between clarity and RP is so blurred for me that when I'm approaching text I try to tell myself to use my native accent and I can't use it because I fall into a pattern of trying to speak RP. That scared me a lot because it feels like now I don't have a voice [...] I don't have a voice! (focus group)

Reading the transcript of this comment gives an insight into some of the practical challenges faced by students. Listening to the recording of the student speaking these words reveals a far 
deeper emotional impact. The affect in the recording communicates a sense of loss, pain, and frustration, and the student goes on to share their disillusionment with a training where they felt that they did not fit in or that their experiences were understood. Focus group findings such as this add to the existing body of research in this area and begin to point toward possible revisions within the training. This research project has also considered industry perspectives to broaden the discussion and set parameters for curriculum revisions that balance the student experience with employability. Data from the survey of actors, and interviews with agents, casting directors, directors, and voice coaches has helped to identify contemporary industry perceptions and demands. While this wider research cannot represent the entire industry, some clear narratives have emerged.

A simple analysis of the survey data shows that all actors are regularly working in their native accent. ${ }^{6}$ Some actors expressed surprise at the amount of time they were working in their own accent compared to expectations they had when they were students. Casting directors and agents support this finding, saying that actors are most likely to be cast in roles using their own accent. One director talked of a strong preference for actors who bring the lived experience associated with a particular accent. For native RP speakers, the number of roles available mean that it is common to sustain work professionally without doing any accent other than their native RP. Agents and casting directors consistently said that they would expect all actors to have learned a "good RP" within their training, despite evidence that many speakers with regional accents were never asked to use RP professionally. This bias toward RP amongst the industry's gatekeepers gives a structural advantage to native speakers and concurs with Friedman and O'Brien's discussion of the somatic norm. They describe a situation where "the only way for somatic 'others' to succeed is to engage in a process of "mimicry" $(2017,6)$. The evidence shows that somatically othered actors are required to demonstrate skills in mimicking the somatic norm, even where this might not be a requirement for the roles that they will be cast in.

A clear set of parameters for the revised curriculum emerged from an examination of these student experiences and industry perspectives. There was a need to address the pedagogy and dominance of RP within foundational speech training to improve the experiences of somatically othered students and, at the same time, there was a need to provide all actors with enough training in RP to meet the needs of industry gatekeepers, even if they would eventually not use the accent in their professional work.

\section{RP within UK Actor Training}

For a large part of the twentieth century, actors in the UK were required to remove all traces of their regional accents and adopt RP for their daily speech. Toward the end of the last century, attitudes shifted, and most UK conservatories now teach RP as part of foundational speech training, but not as a target for everyday speech. This approach is common across English schools and is also used at the Royal Welsh College of Music and Drama and the Royal Conservatory of Scotland. ${ }^{7}$ In many schools, RP is used as the basis for training in the International Phonetic Alphabet (IPA) and as a reference accent from which all other accents are taught; this approach to training is conserved within MA and MFA voice teacher training across the UK.

In 2012, Jan Haydn Rowles and Edda Sharpe published their book How to Do Standard English Accents. In this book, Sharpe and Haydn Rowles attempted to move away from RP's "resonances of authority, social status and economic power" $(2012,8)$ by focusing on the term "Standard English." Prior to this research project, staff on the BA Acting-CDT program also used the term Standard English. Despite this framing as a neutral standard, 
students still described the accent as "posh," "snooty," or "the Queen's English," and aligned it with perceptions of "power," "status" and "class." This is not surprising; the accent has a clear lineage to white, male, upper-middle class education and, even in 1974, was only spoken by $3 \%$ of the population (Trudgill 2000). Students of color described the accent as representing British colonialism, with one student describing it as an accent of the oppressor "something I was forced to learn" (Deborah Garvey, class notes). Socio-linguist, Rosina Lippi-Green, discusses:

The myth of standard language persists because it is carefully tended and propagated [...] The term standard itself does much to promote this idea: we speak of one standard and in opposition, non-standard, or substandard. This is the core of an ideology of standardization which empowers certain individuals and institutions to make these decisions. (Lippi-Green 2000, 28)

Lippi-Green's highlighting of ideology is critical to this discussion and gives weight to Ginther and Knight's demands that actor trainers examine the basic assumptions that underpin their teaching. Ideology affects decisions made at every level of training, and it is vital that long-standing systems do not continue simply because of an adherence to "tradition." Every layer of organizational structure and decision-making needs examining for conscious and unconscious bias. Theatre academic, Katie Beswick, highlights this point:

Although structures of power are rarely directly addressed as an intrinsic element of formal actor training processes [...] students nonetheless absorb understandings about how the "professional industry" works, and about how they are seen and understood by the wider professional world during their training. (Beswick 2018, 7)

Examining the structures of foundational speech training reveals the pervasive invisibility of power in the discourse referred to by Beswick. RP, in the guise of Standard English, maintains a priority within actor training. On the Acting-CDT course, it was the first accent that students encountered and was the only accent taught in the first year. There was an assessment of the accent at the end of that year and, over the course of the entire training, students spent nine months engaging with it, whereas other accents were given a maximum teaching time of ten weeks. Bourdieu (1977) states, "When one language dominates the market, it becomes the norm against which the prices of the other modes of expression, and with them the values of various competencies, are defined" (652). The systemic bias toward RP in actor training has imbued it with, what Bourdieu describes as, "linguistic capital" (646) and, as Beswick points out, students are absorbing that understanding. The structural bias toward RP was only one of the issues that needed to be understood and addressed within this research. The relationship between RP and foundational speech training was also significantly part of the problem.

\section{Speech Training, RP, and the Somatically Othered}

On the BA Acting-CDT program, tutors would explain that they were teaching Standard English as "just another accent," part of a package of American and regional British accents taught within the program. While laudable, this premise becomes complicated when work on Standard English is woven into work on basic speech training and articulation within the first year of training. One of the consistent themes that emerged from the research was a conflict 
experienced by individuals when working on speech clarity (or articulation) alongside training in RP:

There's speaking with clarity and there's [...] basically speaking with RP and the lines between that is blurred [...] when seeing text, I don't feel like I'm prepared to speak in my own voice. There's a paranoia about it. (focus group)

Comments made by actors from other UK drama school backgrounds reinforce the findings within the Acting-CDT case study:

Voice and voice into text classes were focused on my native accent but this was aimed with an RP slant [...] It was constantly reinforced that my voice was not good enough $[\ldots]$ Voice classes trained how to use my own voice, but never encouraged to use it in performance.

These quotes show the confusion that comes from combining RP with work on clarity or articulation. This is further compounded by conflicting messages between voice and speech classes. Many acting courses divide voice and speech into separate classes, often taught by different practitioners. Voice classes focus on finding a connection between thought, feeling, breath, and vocal expression, and teachers will commonly use contested terms such as finding a "truthful" or "authentic" connection in performance. In practice, this authentic connection relates to the ability of the speaker to convey their moment-to-moment thoughts and feelings through their voice as they are speaking, and it leads into later work on the imagined thoughts and feelings of dramatic characters. This foundational voice work on authentic expression is an aesthetic choice that is culturally bound to psychological realism and raises questions of identity and representation that go beyond the scope of this research ${ }^{8}$ Rather than question the content of these voice classes, this research focusses on the conflict experienced by somatically othered students between voice and speech classes. In voice classes, these students are encouraged to find an authentic expression of themselves and at the same time, in speech classes, they learn that this self-expression needs to be managed, tempered, or balanced by the articulation of the word within an RP-based model.

This approach continues a centuries-long tradition of prioritizing the word over the voice. Mladen Dolar traces the recurrence of this tradition from 2200 BCE to the present, describing a tradition where "the voice should not stray away from words which endow it with sense; as soon as it departs from its textual anchorage, the voice becomes senseless, threatening" (Dolar, 2006, p. 43). Philosopher, Adriano Cavarero, states that "the voice is the equivalent of what the unique person has that is most hidden and most genuine. [... It is] a deep vitality of the unique being who takes pleasure in revealing herself through the emission of the voice" $(2005,4)$. For the actor who deviates from the somatic norm, the dominant message is that their individual uniqueness must be contained by a more "acceptable" pattern of speech; that their difference is, as Dolar indicates, a threat to the listener. This conflict lies behind the statement from the student, quoted above: "now, I don't have a voice. [...] I don't have a voice!"

Socio-linguist, Scott F. Kiesling, explores this relationship between voice and speech from a class perspective and describes how "Class is [...] experienced and felt, and it is something that seems to inhere deeply into bodies, and not just the way people talk" (Kiesling 2018, 253). This understanding of the inherence of intersections of identity into bodies, beyond what is identifiable in speech, relates to Cavarero's discussion of the hidden "genuine self" and is crucial in the evaluation of voice and speech training. If foundational first-year classes include speech work that aims to "correct" the way people talk, alongside voice work 
that aims to teach an embodied vocal expression of the "hidden" self, then this creates a schism in the identity of the somatically othered student. ${ }^{9}$

Returning to Bourdieu, arguably, the training infers to somatically othered students that their existing socio-linguistic capital is of less value than the linguistic capital of those who conform to the somatic norm. For somatically othered students who arrive to training with limited economic or cultural capital the rejection of their existing resources of sociolinguistic capital can be deeply unsettling. African American voice teacher, Stan Brown, articulated his experience of this process during the American speech debate in 2000. Brown describes a moment in his training when his teacher told him "Well Stan, you know the English Language doesn't really belong to you...your culture." He notes, "the sounds of my speech reflected the social and geographical environment of my life experiences, thus far. Those were the only sounds I could speak to assert my identity" (Brown 2000, 17). Brown's experience echoes that of the UK actors and students outlined in this research and reinforces the demand for a training that values students' existing socio-linguistic capital and enables them to develop foundational performance skills that do not require a mimic of the somatic norm.

Drawing on this understanding, key changes were made to the Acting-CDT training. First-year voice work was adapted to include work on intersectional identities and voice. This included work that allowed students to explore multiple everyday vocal performances - codeswitching or, as queer voice scholar, Yvon Bonenfant, would call it, vocal styling (Bonenfant 2018). This identity-focused voice work was complemented by speech work that engaged with students' "everyday speech patterns." This work on everyday speech patterns replaced the previous first-year training in RP and articulation. Training in RP was moved to the second-year as part of that year's focus on accents and dialects for performance. In effect, RP has now become "just another accent" as it is the last accent to be taught and is unrelated to the foundational speech work. These structural changes were not enough in themselves. As the curriculum was developed it became necessary to consider the language of instruction, the pedagogical approaches used, and the value systems on which all of this was based.

\section{Decentering Language, Methods, and Pedagogy.}

This research project required a rigorous re-evaluation of the language of instruction as many of the terms used within traditional approaches to speech training normalize the dominant "values of various competencies" (Bourdieu 1977, 652). One such term is "native accent," which several focus group participants found problematic. International students, particularly, commented on confusion with this term, describing how, when speaking a second language, there is always an implied target accent that moves their speaking away from any sense of "native" speech patterns. Others described how they regularly code-switch in a way that belies any sense of a fixed or "native" accent. Socio-linguist, Reem Bassiouney, echoes these perceptions when she states that "an individual's linguistic choices are not just natural but performed" (Bassiouney 2018, 1). By focusing on everyday speech patterns, in a move away from the essentializing of native accents, the revised training's focus engages with this "performance of identity." Accent is seen as one of many features of everyday speech that can be performed as part of multiple, context specific, vocal identities and the range of sounds that any individual draws on is now referred to as their "individual sonic palate."

Prior to this research, students were taught articulation as part of foundational speech work. The use of articulation as a descriptor implies a speech standard as a $\operatorname{target}^{10}$. Previously, these speech classes would begin with work to address the manner and placement of specific speech sounds before moving on to language and text. In the revised curriculum, this process is reversed to avoid a standardizing approach. Instead of focusing on the manner 
and placement of specific speech sounds, the work starts by examining the communication needs of specific texts from the perspective of each individual's everyday speech patterns. In the first iterations of this revised curriculum, articulation was replaced by the terms "clarity and specificity," with a focus on enabling the student-actor to be "understood" (journal notes). As is common with many British schools, poetry is taught to engage students with language without the need to explore characterization. A program of work was proposed using poems that incorporated "progressively more complex speech structures." When considering what these speech structures might be, it was suggested that they might include consonantal sounds such as the plosive sounds of "Give me a gift of a grip top sock," or "dark l's" (velarized alveolar lateral approximant) on the ends of words as in "Little kettle made of metal," or complex consonant clusters such as "Amidst the mists and coldest frosts" (journal notes) ${ }^{11}$.

At this point in the research methodology, a deeply significant moment of illumination occurred:

I've just realized that, despite trying to focus on speech from the perspective of students' everyday speech patterns, I am choosing texts based on their consonantal components and that all the challenging sounds that I am trying to include are consonants that are associated with the articulation of RP. I realize now, that, every time I ask an actor to add a clear/t/ or dark-L to the end of a word in the pursuit of "clarity," I am actually moving them incrementally toward RP, as if clarity is somehow encoded into those individual consonant sounds. This is suddenly glaringly obvious, but my bias toward RP has been so deeply unconscious that I couldn't see it before. (journal notes)

This moment of illumination began to decenter my value system and led me into the heuristic research phase of "explication," which "involves examining what has arisen and coming to an understanding of what meaning it might hold" (Kenny 2012, 8). During this phase the critical framework of colonized listening practices proposed by sound studies academic, Jennifer Lynn Stoever, helped me to make sense of my disoriented value system. In her book, The Sonic Color Line: Race and the Cultural Politics of Listening, Stoever calls for a decolonization of listening as she discusses the evolution of racialized listening in the US from 1845 to 1945. At the heart of her book are two key concepts. The first is the "Sonic Color Line," which "connects sound with race in American culture, showing how listening operates as an organ of racial discernment, categorization, and resistance" (Stoever 2016, 4). Key to this process is what Stoever refers to as the listening ear:

I offer the Listening Ear as the ideological filter shaped in relation to the sonic color line $[\ldots]$ The listening ear enables the key dichotomies of the sonic color line $[\ldots]$ it normalizes the aural tastes and standards of white elite masculinity as the singular way to interpret sonic information. (Stoever 2016, 13)

The normalizing function of the listening ear in Stoever's critical framework can be related to the somatic norm within the performing arts. The somatic norm requires somatically othered actors to engage in some degree of mimicry of the somatic norm for success. This combines with speech training that listens for intelligibility by endowing RP consonants with the power of clarity. From this perspective, it is possible to perceive the presence of an invisible listening ear in every studio and rehearsal room, to which training and performances are constantly being tuned. Adapting the listening ear to the UK performing arts context in this 
way extends its reach beyond the intersection of race and gender explored by Stoever to include a listening bias that normalizes the aural tastes of middle and upper-class speakers of RP or Standard English.

My journal notes revealed a further moment of heuristic illumination during this stage of critical reflection:

I've just remembered the moment in my voice teacher training when a senior voice teacher responded to the way I said the word "tune" with, "you won't be able to work in this voice department if you say choon and not tyoon." 12 This did not happen in an $\mathrm{RP}$ accent class but in a voice class, and the desire for tyoon was predicated on the need for speech clarity. I felt angry at the time but then made the change to my speech out of a desire to be more employable. As a teacher, I soon began to listen for the very same markers of speech clarity. I realize now, that this was part of a process in which my already unconsciously colonized White East-Midlands, working-class, ear was further colonized by my training. (journal notes)

This is a useful example of a need for those who are somatically othered to mimic the somatic norm for success. Voice teacher, Micha Espinosa, shares this experience when she discusses how she abandoned her own socio-linguistic capital for economic gains. Espinosa describes stepping away from her Latina roots as she "entered the world of theatre. There, cultural and monetary capital was acquired by entering the dominant culture. "To gain entrance, I abandoned my voice" (Espinosa 2011, 78). The influence of the somatic norm, coupled with a desire for economic capital is incredibly powerful, and it is vitally important that voice teachers examine the extent to which their listening ears have been colonized by their own training. Stan Brown highlights a lack of awareness of these processes of colonization when he asks:

Why do many teachers never cite white culture [...] as the source-creators of standard speech for the stage? Why is a speech standard that predates a consistent presence of minority actors in mainstream theatre [...] still used in multicultural professional training programs? (Brown 2000, 18)

Over 18 years later, in their 2018 article on standard dialect teaching in the US, Melissa Tonning-Kollwitz and Joe Hetterly describe a "growing awareness and desire for better contextualization of the inherent racial, social, and economic implications of standard dialects" but offer no examples of changes in practice beyond work that moves the focus onto clarity and intelligibility (Tonning-Kollwitz and Hetterly 2018, 311). Descriptors such as clarity have the same colonizing effect as articulation and RP. One student says of clarity, "I think I am further from my accent because of clarity. Because to be clear, it sounds like [...] Like, if you put clarity in the words it changes the sound of them" (focus group). Dudley Knight suggests:

We grant a graceful retirement, with a generous pension, to the word that had been such a friend and comfort to us all over the long years: clarity. Clarity as a term that has become too polluted through time. (Knight 2000, 72)

In the American standard speech debate, Knight brought this discussion to a conclusion by proposing "intelligibility" as a replacement for clarity. He describes intelligibility as "an alert listener's perceptions of the speaker's physical actions of articulation that turn a string of sounds into communication of the most basically denoted level" (72). The question that arises 
from a focus on intelligibility is "who is doing the listening, who defines intelligibility?" Knight is clear on this, "most theatre accent coaches have a keen experiential awareness of what intelligibility is, because they have to modify accuracy of accent all the time" $(2000$, 75). He goes on to describe how when listening on the most basic level of intelligibility "all ideology and complex analysis falls away." Stoever's critical framework, however, has shown that "although often deemed an unmediated physical act, listening is an interpretive, socially constructed practice conditioned by historically contingent and culturally specific value systems riven with power relations" $(2016,14)$, and I have shown how coaches' listening practices can be further constructed and colonized by their training. Knight's proposition was a valuable step forward in 2000, moving from an approach based solely on standards to one that focused on "intelligibility." Nevertheless, revisiting this proposition with the insights of this research and the critical frame of the listening ear, it is clear that ideology cannot simply "fall away" and that coaches need to decolonize their listening and interrogate their practices for conscious and unconscious bias toward the somatic norm.

I was reticent to adopt a decolonizing framework within this research. As a privileged white man, albeit somatically othered by my class background, regionality, and sexuality, my experience sits outside of the intersection of identities at the heart of the radical politics of decolonization. As decolonization gains ground, academic bloggers, Sisters of Resistance, Left of Brown, and Jenny Rodriguez, rightly "interrogate the acceptability of decolonizing rhetoric as a sign that it is becoming co-opted by capital" (Brown and Rodriguez 2018, 1). ${ }^{13}$ They go on to state that decolonizing requires "engaging with Whiteness with a sense of responsibility and self-accountability" and that "if you are not upsetting Whiteness by doing the work, you are not doing the work" (Brown and Rodriguez 2018, 1).

My own process has been one of growing awareness of my accountability as a white man. The resistance that this research has been met with from some quarters indicates that it is to some extent upsetting Whiteness. Some voice colleagues reject the propositions of this research saying that the issues described here must be particular to students on the ActingCDT program (inclusive practice forum). Others state that the proposed revisions would not be appropriate in their school as "there's a certain expectation of the teaching at the school" or that they "need to meet the demands of industry" (inclusive practice forum). All these positions perpetuate the dominance of the somatic norm and ignore the evidence from this research that shows it is possible to meet the needs of industry and that of somatically othered students equally. Decolonization is intersectional and, while the core of this discussion draws on theories of anti-racist listening practices, the revised curriculum benefits all intersectional identities that are othered by the somatic norm in the performing arts.

The examples given above show how training, which favors the somatic norm, can further colonize the listening ears of voice coaches. It is important to remember that much of the colonization is societal and happens unconsciously, that the somatic norm and the listening ear are rendered invisible and inaudible precisely because the white, male, middle to upper-class body is defined as the standard, from which all others are seen as diverse. Sociolinguist, Michelle Hall Kells, asserts, "speakers of stigmatized language varieties internalize the social norms and linguistic value judgments of the dominant group" (Kells 2002, 11). This internalization of the somatic norm is evident in discussions with first-year students. Somatically othered students readily describe how, prior to their training, they have given performances in which they have moved away from their everyday speech patterns toward RP, yet when asked why they chose to do this, they are unable to explain (journal notes). The normalizing impact of the listening ear affects actors, coaches, directors, and audiences and there is a radical need to decolonize the listening of students to begin to stem the perpetuation of the somatic norm within the industry. 
The revised speech curriculum on the Acting-CDT course begins with an exercise that engages directly with this very issue. Students record themselves speaking to a friend about something that they would like to change in the world. In class, the group listens to these recordings. After listening, the group generally agrees that the persuasive nature of the speaking enabled all the speakers, across a wide variety of accent groupings, to be understood by everyone in the room. ${ }^{14}$ This simple experiment sets the context for the rest of the training, which is built on the assumption that all accents have the potential to be understood and there is no need to modulate the accent toward a speech standard. This simple but profound change in perspective grounds all the subsequent training within a framework of equality, which aims to engage the unique sonic palette of each student in a desire to affect change through their speech.

Students are encouraged to bridge the divide between voice and speech classes and link both to principles of acting by speaking with a desire to affect change in the listener, rather than focusing on being intelligible. The word "affect" is used to denote a move beyond the $e$-ffectiveness of clarity, intelligibility, and other similar terms and follows the "affective turn" in the humanities and social sciences.

Sociologist, Patricia Clough, describes how this affective turn grows out of a focus on the body within feminist theory and an exploration of emotions within queer theory (Clough and Halley 2007, ix). She goes on to state that "the perspective of the affects requires us constantly to pose as a problem the relation between actions and passions, between reasons and the emotions" $(\mathrm{x})$. This engagement with action and reason, passion and emotion, relates the discussion of affect directly with discourses of actor training. Affect is also used more specifically in relation to language, across anthropology, ethnography, and socio-linguistics. Ethnographer, Niko Besnier, describes how "affective meaning is seen as encoding of the speaker's emotions, which the interlocutor decodes in verbal messages by giving precedence to intentionality" (Besnier 1990, 420). This practice of listening for intentionality through affect provides a blueprint for a decolonized listening practice.

At the heart of the new curriculum is a focus on teaching listening. In his discussion of decolonization and the epistemologies of the south, sociologist, Boaventura de Sousa Santos, advocates "deep listening" and describes how "schools teach how to speak but not how to listen" (de Sousa Santos 2018, 176). By teaching students to listen deeply for the affect of intentionality through the impact of sounds on their bodies and emotions, rather than listening for effective clarity of speech, there is an opportunity to decolonize their listening ears.

Over the course of the first term ${ }^{15}$ of training, students spend time listening to and analyzing their recordings of themselves to identify the everyday speech features captured in that moment of affective speaking. The students become experts in the manner and placement of their own speech patterns by comparing their linguistic identity with that of their peers. At the end of the term, they recreate their recorded speech in a live performance. This challenges them on three levels. First, they need to understand their speech patterns well enough to accurately recreate them. Second, they need to employ vocal skills to translate the mediatized recording effectively into a theatrical performance space, and, third, they need to use their acting skills to actively affect the audience, as if speaking the words for the first time.

In the second term of training, students work on poetic text from the perspective of affective speaking and listening. These affective speech classes run concurrently with other classes on voice and text and ask students to engage directly with the relationship between the perceived intention of the author and the actor's unique sonic palette. There is limited scope to discuss the content of these classes here and the example below is offered as a brief insight into the revised approach, describing an exercise in affective speaking and listening using Derek Walcott's poem “Bleeker Street Summer” (Walcott 1992, 40). 
In this exercise, students work in pairs-where possible, each pair includes speakers from different accent groupings. The pairs spend a little time investigating Walcott as an author and consider possible intentions he may have had when writing the poem. ${ }^{16}$ After this preliminary exploration, the pair begin to work through the text, line by line. Each person will speak the text out loud and their partner will listen, asking themselves, "What sounds can I hear that might affect the listener in a way that relates our perceptions of the writer's intention?" After a discussion of this, artner A will speak the line again and try to achieve that affect a little more consciously. Partner B will listen and coach, focusing on aspects such as "can you find more of the rhythm of New York in 'down littered streets,' to contrast with the expansive feel of 'gathering islands' in the next line?" In this way, each student is encouraged to draw on their own unique sonic palate to meet the perceived affective possibilities within the text. When the pair have finished working on the poem, they meet with another pair, $\mathrm{C}$ and $\mathrm{D}$, who have been working on a different poem. $\mathrm{C}$ and $\mathrm{D}$ become the audience as $\mathrm{A}$ performs the Walcott poem. While A is speaking the poem, B will stand beside them and listen as coach. $\mathrm{C}$ and $\mathrm{D}$ give an immediate response to A, which can include any thoughts, feelings, images, etc., sharing how receiving the spoken poem affected them. When $C$ and $D$ have given their responses, B then gives A coaching feedback, reflecting on which aspects of the preparatory work remained in performance and which areas might need to be revisited to be more affective in future.

This exercise can be extended beyond work on poetry to "affective" texts such as political speeches, and then into work on scenes that require the actors to use their everyday speech patterns. When working on scenes, the actors begin to ask, "What sounds can I hear that might affect the other characters in the scene in a way that relates to what the speaking character wants?" This work enables actors to connect their speech work immediately into a character's desire to affect change rather than having a split focus, where part of their attention is focused on "being intelligible."

Another advantage of this work on affective listening and speaking is the democratization of listening in the classroom. Practicing listening across accent groupings helps to avoid the risk that students might hold on to RP as a model for speech clarity. This risk is more likely if the teacher themselves speaks with an RP accent, as their position of power gives their own accent an unconscious normative authority within the room. Many voice teachers in the UK predominantly conform to the somatic norm with the performing arts, and any pedagogic strategies that can help to decenter the normalizing power of that is to be welcomed. The coaching model outlined above moves the process away from vertical listening by the "expert" teacher, toward horizontal listening of a co-collaborator who stands besides and supports the speaker. This approach is part of a fundamental shift within the training toward a critical or radical pedagogical framework. In this revised model, student coaches help each other to discover possibilities of affect within the text, rather than imposing certainties of effective pronunciation coded by unconscious or conscious ideas of speech clarity or intelligibility. This approach reinforces the connection between voice, speech, and acting, and it enables the actor to use the full performative range of their unique vocal and linguistic identity.

\section{Conclusion}

This research illustrates how the dominance of the somatic norm within conservatory training and the performing arts industries has combined with a historical approach to speech work that prioritizes RP as a model for speech clarity to reinforce the colonized listening ears of students, voice practitioners, actors, directors, and audiences. The research indicates that while there is a need for some training in RP to meet the needs of industry gatekeepers and 
the potential employment of some actors, RP training needs to be separate from foundational work on speech. This research also suggests that there is no need for actors to adapt their everyday speech patterns toward a standard model to achieve intelligibility and that when this does happen, the conflation of speech training with RP may have a negative impact on the experiences of somatically othered actors. The solution to this problem requires a paradigm shift in the ideology of listening that is applicable to any actor training context where there is a desire to work equitably. As argued in this research, there is a need to reject the myth that certain speech patterns are more intelligible than others, and this shows a deeply held unconscious bias toward the somatic norm.

The reframing of practice from effective to affective speech might be construed as subtle semantics, but the resulting practice, which rejects accent standards, articulation, and clarity and intelligibility as the focus for foundational speech work, involves a radical reworking of the curriculum and repositioning of knowledge and practice within the acting studio. Training actors in the affective use of their unique sonic palate aligns speech work more closely with acting principles. The model of affective speaking and listening outlined here supports actors to assume the right to speak without mimicry of the somatic norm and celebrates and enhances their pre-existing socio-linguistic capital. The benefits of this model are evident in the focus group comments of students who took part in the revised training:

It's quite interesting, because I feel like my accent is more my accent now than it ever was. If that makes sense? I feel like my accent has got more southeast London when I've come to drama school. Which is interesting, because someone said, "I don't think that would have happened. They would have made you try to sound more RP."

I recognize my voice as being present [...] I feel as if I now have a back catalogue of the effect of sounds [...] Now, I feel like, if I was to go out into the industry, I know my voice well enough to be able to use it to the best of my ability.

A lot of my feedback before drama school was that I had really poor diction [...] I now, myself, would be comfortable to be able to say, "I can go on the stage and talk as me, and almost everyone will understand."

If student actors, whose intersectional identity does not conform to the somatic norm, encounter resistance to the expression of the full range of their identity within their training, then training institutions are complicit in the process of somatic othering. By developing more equitable practices within training, there is the potential for a groundswell of actors from pluralistic backgrounds assuming their right to speak as themselves: "inside outsiders" with the collective power to affect change within the industry through their own voices.

\section{Acknowledgements}

I would like to acknowledge the contribution of Deborah Garvey and Louise Jones as cocollaborators on the practice-based element of this research project. I am grateful for their trust and commitment to this project and their valuable insights along the way.

\section{References}

Bassiouney, Reem. 2018. Identity and Dialect Performance: A Study of Communities and Dialects. Abingdon: Routledge. 
Besnier, Niko. 1990. "Language and Affect." Annual Review of Anthropology 19: 419-451. Beswick, Katie. 2018. "Playing to Type: Industry and Invisible Training in the National Youth Theatre's 'Playing Up 2'." Theatre, Dance and Performance Training 9 (1): 418. doi:10.1080/19443927.2017.1397542.

Bhopal, Kalwant. 2018. White Priviledge: The Myth of a Post-Racial Society. Bristol: Policy Press.

Bonenfant, Yvon. 2018. "Your Voice is Hair: Speculations Toward a Metaphor for Styling Vocal Identity." Journal of Interdisciplinary Voice Studies 3 (2): 143-166. doi:10.1386/jivs.3.2.143_1.

Bourdieu, Pierre. 1977. "The Economics of Linguistic Exchanges.” Social Science Information 16 (6): 645-668.

Brabin, Tracy, Gloria De Piero, and Sarah Coombes . 2017. Acting Up Report: Labour's inquiry into access and diversity in the performing arts. Labour Party Enquiry Report, London: The Labour Party.

Brown, Left of, and Jenny Rodriguez. 2018. Sisters of Resistance. 12th July. Accessed February 18th, 2019. https://sistersofresistance.wordpress.com/2018/07/12/isdecolonizing-the-new-black/.

Brown, Stan. 2000. "Column The Cultural Voice." Voice and Speech Review 1 (1): 17-18. doi:10.1080/23268263.2000.10761381.

Bryon, Experience. 2014. Integrative Performance Practice: Practice and Theory for the Interdisciplinary Performer. Abingdon: Routledge.

Clough, Patricia Ticineto, and Jean Halley. 2007. The Affective Turn: Theorizing the Social. Durham, NC: Duke University Press.

Dal Vera, Rocco. 2000. "Letter from the Editor." Voice and Speech Review 1 (1): 4.

de Sousa Santos, Boaventura. 2018. The End of the Cognitive Empire: The Coming of Age of the Epistomologies of the South. Durham: Duke University Press.

Espinosa, Micha. 2011. "A Call to Action: Embracing the Cultural Voice or Taming the Wild Tongue." Voice and Speech Review 7 (1): 75-86. doi:10.1080/23268263.2011.10739524.

Espinosa, Micha, and Antonio Ocampo-Guzman. 2010. "Identity Politics and the Training of Latino Actors." In The Politics of American Actor Training, edited by Ellen Margolis and Lissa T Renaud, 150-161. New York: Routledge.

Friedman, Sam, and Dave O'Brien. 2017. "Resistance and Resignation: Responses to Typecasting in British Acting." Cultural Sociology 11 (3): 359-376. Accessed August 5th, 2019. doi:10.1177/1749975517710156.

Ginther, Amy. 2015. "Dysconscious Racisim in Mainstream British Voice Pedagogy and its Potential Effects of Students from Pluralistic Backgrounds in UK Drama Conservatoires." Voice and Speech Review 9 (1): 41-60. doi:10.1080/23268263.2015.1079773.

Kells, Michelle Hall. 2002. "Linguistic Contact Zones in the College Writing Classroom: An Examination of Ethnolinguistic Identity and Language Attitudes." Written Communication 19 (1): 5-43.

Kenny, Gerard. 2012. "An Introduction to Moustakas's Heuristic Method.” Nurse Researcher 19 (3): 6-11. doi:10.7748/nr2012.04.19.3.6.c9052.

Kiesling, Scott F. 2018. "YouTube Yinzers: Stance Taking and the Performance of 'Pitsburghese."' In Identity and Dialect Performance: A Study of Dialect Communites, edited by Reem bassiouney, 245-264. Abingdon, Oxon: Routledge.

Knight, Dudley. 2000. "Standards." Voice and Speech Review 1 (1): 61-78. doi:10.1080/23268263.2000.10761387. 
Lippi-Green, Rosina. 2000. "The Standard Language Myth.” Voice and Speech Review 1 (1): 23-30. doi:10.1080/23268263.2000.10761384.

McAllister Viel, Tara. 2019. Training Actor's Voices: Towards an Intercultural/Interdisciplinary Approach. Abingdon: Routledge.

McGee, Beth. 2005. ""White like me"; Racism, Cultural Identity and Voice." Voice and Speech Review 4 (1): 144-150. doi:10.1080/23268263.2005.10739459.

McLeod, J. 2011. Qualitative Research in Counselling and Psychotherapy. London: Sage Publiations.

McNamara, Catherine, and Nicholas Coomber. 2012. BME Student Experiences at Central School of Speech and Drama. HEA Funded Research Project, York: Higher Education Academy.

Moustakas, Clark. 1990. Heuristic Research: Design, Methodology, and Applications. Newbury Park, CA: Sage.

Oram, Daron. forthcoming. "Chekhov Technique and Voice." In Michael Chekhov Technique in the Twenty First Century: New Pathways. London: Bloomsbury Methuen Drama.

Pete, Shauneen. 2018. "Meschachakanis, a Coyote Narrative: Decolonising Higher Education." In Decolonising the University, by Gurminder K. Bhambra, Dalia Gebrial, and Kerem Nişancioğlu, 173-189. London: Pluto Press.

RCSSD. 2018. BA Acting: Collaborative and Devised Theatre. Accessed August 21st, 2018. https://www.cssd.ac.uk/course/acting-cdt-ba.

Sharpe, Edda, and Jan Haydn Rowles. 2012. How to do Stadard English Accents. London: Oberon Books.

Stoever, Jennifer Lynn. 2016. The Sonic Color Line: Race and the Cultural Poltics of Listening. New York: New York University Press.

Ticiento Clough, Particia, and Jean Halley. 2007. The Affective Turn: Theorizing the Social. Durham, NC: Duke University Press.

Tonning-Kollwitz, Melissa, and Joe Hetterly. 2018. "The Current Use of Standard Dialects in Speech Practice and Pedagogy: A Mixed Method Study Examining the VASTA Community in the United States." Voice and Speech Review 12 (3): 293-313. doi:10.1080/23268263.2018.1500195.

Trudgill, Peter. 2000. "Sociolinguistics of Modern RP." University College London. Decemeber 8. Accessed 08 21, 2018. https://www.phon.ucl.ac.uk/home/estuary/trudgill.htm.

Walcott, Derek. 1992. Collected Poems 1948-1984. London: Faber and Faber.

\footnotetext{
${ }^{1}$ The terms BAME (Black, Asian and Minority Ethnic) and BME (Black and Minority Ethnic) are commonly used in UK equity, diversity, and inclusion discourse. These terms are contested by many. In this article, I have used them in relation to writing where others have used those terms. Where possible I have used Students/Actors/People of Color, which is the term used more commonly by my own students.

${ }^{2}$ Standard American Stage is an accent taught within American actor training. The accent is sometimes known as mid-Atlantic as it has reduced r-coloring or rhoticity. The accent is an acquired accent and does not come from any specific geographical location.

${ }^{3}$ Garvey is a lecturer at Central, and Jones is a visiting (adjunct) lecturer on the BA ActingCDT course. They delivered some of the revised curriculum and took part in reflective discussions, planning, and peer review.

${ }^{4}$ In the last 12 months alone, graduates of the course have performed significant roles in "traditional" productions at the Almeida, National Theatre, Royal Shakespeare Company, Young Vic, The Globe, and in films such as Star Wars and Downton Abbey.
} 
${ }^{5}$ There is a wider discussion to be had on the impact of diverse intersectional identities within performing arts and the challenge that this presents to naturalism. This is the focus of a simultaneous research project that I plan to publish in the future.

${ }^{6}$ Overall, 23 of the 58 actors surveyed identified as having a "native" accent close to RP. $95 \%$ of those RP speakers said that they regularly used RP professionally, with $48 \%$ of RP speakers also regularly working in other accents. $82 \%$ of the non-RP speakers regularly worked in their native accent. $51 \%$ of them also regularly worked in RP, and $60 \%$ of them worked regularly in accents other than their native accent or RP.

${ }^{7}$ There are currently no accredited actor training courses in Northern Ireland. The RWCMD are currently working to broaden the range of accents taught on their courses, and the RSA do include work on Scots language and speech as part of a broader package of accent and dialect work.

${ }^{8}$ Ginther (2015) discusses some of these challenges, as does Tara McAllister-Viel (2019) and Experience Bryon (2014). I have similarly been researching the impact of the "natural" or "free" voice approach on somatically othered actors alongside this research into speech and accents and intend to publish this work in the future.

${ }^{9}$ I explore the impact of this voice/speech schism from a neuroscientific perspective in my book chapter on Michael Chekhov technique and voice (Oram forthcoming).

${ }^{10}$ Accent specific articualtion practice is incorporated into transformational accent work in the second year of training.

11 These short poems and articulatory exercises have been passed on verbally from teacher to teacher over time.

${ }^{12}$ The preference here is for the RP related /tju:n/ rather than my regional /t $\mathrm{fu}: \mathrm{n} /$, which had already been modified from my East Midlands /tu:n/ after a decade of living in London.

${ }^{13}$ Traditional academic discourse can silence or marginalized the voices of Academics of Color. To open up and challenge the dominant narrative, blogs, etc. offer a necessary and valid source of commentary.

${ }^{14}$ Occasionally, English as Second Language speakers express some difficulty in understanding, but this is usually related to the speed of speech and the ability to understand the language content, rather than the delivery.

${ }^{15}$ Most UK training is divided into three terms, rather than semesters, running Oct-Dec, JanMar and April-July.

${ }^{16}$ Walcott was born in St. Lucia and spent time living in New York, and this poem weaves Caribbean imagery with the sights and sounds of Greenwich Village. 